\title{
Sporadic Burkitt Lymphoma with Orbital Extramedullary Infiltration
}

\author{
Sruthi Arepalli ${ }^{a} \quad$ Aron Flagg $^{b} \quad$ Arthi Venkat $^{a} \quad$ Arun D. Singh ${ }^{a}$ \\ ${ }^{a}$ Cole Eye Institute, Cleveland Clinic Foundation, Cleveland, OH, USA; ${ }^{b}$ Department of Pediatric Hematology/ \\ Oncology and Blood and Marrow Transplant, Cleveland Clinic, Cleveland, OH, USA
}

\section{Established Facts}

- Sporadic Burkitt lymphoma is rarely associated with orbital involvement.

\section{Novel Insights}

- We present a case, with photographic and radiological evidence, of sporadic Burkitt lymphoma with extramedullary subperiosteal leukemic infiltrates of the orbit, which resolve with chemotherapy.

\section{Keywords}

Sporadic Burkitt lymphoma · Subperiosteal infiltrates ·

Chemotherapy

\begin{abstract}
Background/Aims: Sporadic Burkitt lymphoma is rarely associated with orbital involvement. Methods: We present a case of sporadic Burkitt lymphoma with extramedullary subperiosteal leukemic infiltrates of the orbit and facial bones. Results: Follow-up examination after chemotherapy and disease remission reveals resolution of the subperiosteal infiltrates. Conclusion: Despite an aggressive presentation, cure is common with appropriate, intensive treatment. To our knowledge, this report is the first to photographically depict the resolution of extramedullary orbital subperiosteal leukemic infiltrates after appropriate chemotherapy.
\end{abstract}

(c) 2018 S. Karger AG, Basel

\section{KARGER}

(c) 2018 S. Karger AG, Basel

E-Mail karger@karger.com

www.karger.com/oop

\section{Introduction}

Burkitt lymphoma is a B-cell, non-Hodgkin lymphoma, which was first described by Dr. Burkitt as a sarcoma involving the jaw in African children in 1958 [1]. Since then, the classification scheme has expanded to include 3 categories: endemic, sporadic, and immunodeficiency associated [2]. All 3 forms involve a translocation of the $c$ $m y c$ gene on chromosome 8 with chromosome 14 (and less commonly 2 or 22), resulting in an inappropriate overexpression of B cells $[2,3]$. On the whole, Burkitt lymphoma is an aggressive malignancy, with a doubling time of approximately $24 \mathrm{~h}$, which accounts for $40 \%$ of all childhood non-Hodgkin lymphomas. The endemic form is associated with equatorial Africa and Papua New Guinea and has a higher concurrent incidence of the EpsteinBarr virus. This subset typically presents with explosive facial disfiguration. The sporadic form is associated with 

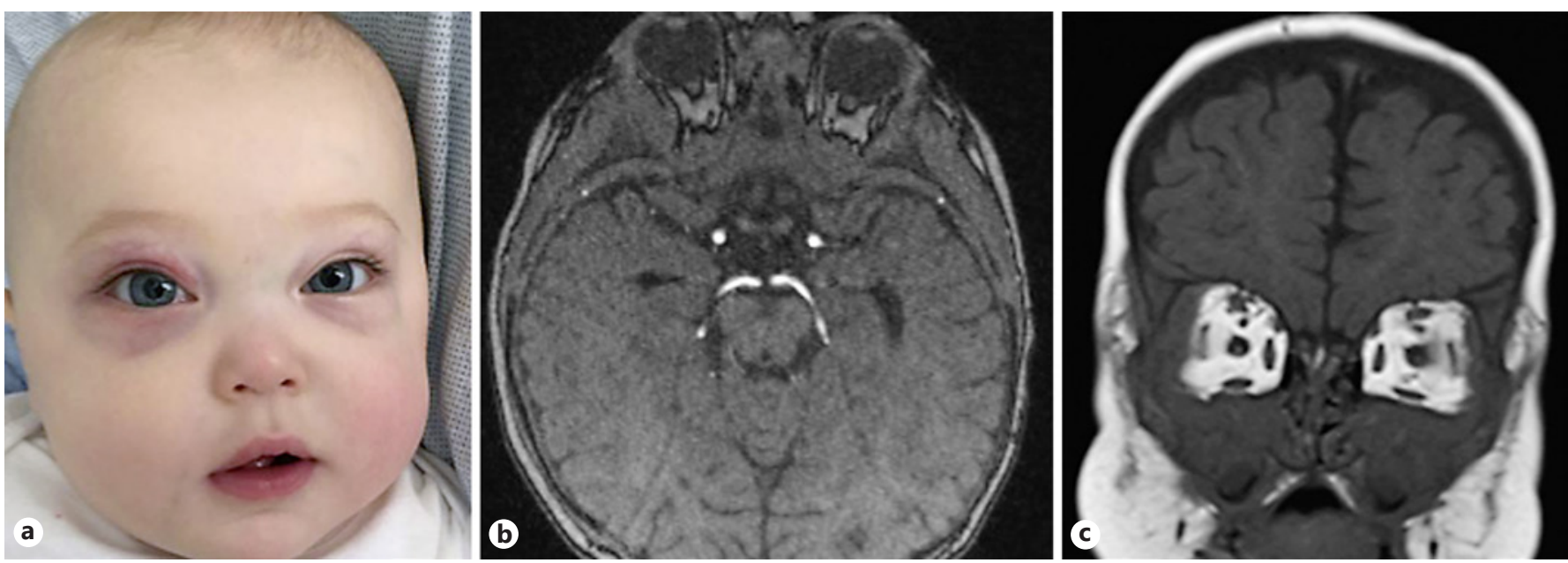

Fig. 1. a External photograph showing bilateral eyelid swelling, with the right eye more involved than the left one. b Axial magnetic resonance imaging (MRI) through both orbits reveals a homogenous infiltrate throughout both, without involvement of the ocular muscles or globe. c Coronal MRI reveals orbital involvement as well.

nonendemic areas, such as America, and usually presents with an abdominal mass [4]. Orbital involvement in the sporadic variant is rare and can mimic other inflammatory or infectious processes. Given its potentially fatal outcomes and its impressive response to treatment, it is imperative to recognize the disease even with atypical presentations [5].

Herein, we describe a case of a 7-month-old male presenting with facial and orbital swelling from sporadic Burkitt lymphoma, as well as documentation of resolution after chemotherapy.

\section{Case Report}

A 7-month-old Caucasian male, born full term without any previous medical history, presented with fussiness, nausea, vomiting, and periorbital swelling. The patient was initially discharged with the diagnosis of a viral upper respiratory infection but returned 3 days later with worsening symptoms and increased periorbital swelling.

On his return visit, ophthalmology was consulted for worsening facial swelling. Ophthalmological examination was pertinent for a visual acuity of fix and follow in both eyes, equal and reactive pupils, and normal pressures to palpation. External examination was significant for ecchymosis and swelling of the upper and lower right lids, extending into the cheek, with slight edema on the left lids as well (Fig. 1a). Anterior segment and fundus examination were unremarkable otherwise. Magnetic resonance imaging (MRI) of the face and head showed diffuse subperiosteal infiltrates involving the facial bones, base of the skull, and frontal and temporal bones. There did not appear to be direct involvement of the extraocular muscles, optic nerve, or globe (Fig. 1b, c).

Sporadic Burkitt Lymphoma with Orbital Extramedullary Infiltration
At that time, laboratory work was significant for thrombocytopenia $(77 \mathrm{k} / \mu \mathrm{L})$, neutropenia $(0.68 \mathrm{k} / \mu \mathrm{L})$, increased lactate dehydrogenase $(>2,500 \mathrm{U} / \mathrm{L})$, and increased uric acid $(8.2 \mathrm{mg} / \mathrm{dL})$. Serology was negative for Epstein-Barr virus IgM and IgG antibodies. A peripheral blood smear showed neutropenia, thrombocytopenia, and $25 \%$ circulating blasts. These blasts were large, with brightly basophilic cytoplasm, rare cytoplasmic granules, and prominent vacuolization. They exhibited multilobed nuclei and prominent nucleoli.

Flow cytometry confirmed that the blasts were lymphoid B cells that diffusely expressed CD19, along with dim expression of CD10, CD20, CD22, CD38, and CD45. Kappa and lambda expression, as well as terminal deoxynucleotidyl transferase, and markers of T cells were absent. Immunohistochemistry revealed the CD20+ cells to be likely normal background lymphocytes. A bone marrow biopsy showed effacement by acute leukemia with blasts displaying a vacuolated morphology similar to the peripheral blood (Fig. 2a, b). Chromosomal analysis revealed reciprocal translocation of chromosomes 8 and 14, as well as multiple cells containing 2 extra copies of the long arm of chromosome 1 in the form of an isochromosome. Lumbar puncture revealed rare leukemic blasts in the cerebrospinal fluid, confirming central nervous system involvement. Given the MRI findings and facial swelling in conjunction with bone marrow changes, the diagnosis of sporadic Burkitt lymphoma/leukemia with extramedullary subperiosteal infiltration was made.

The patient was treated similar to the FAB LMB96 protocol [6], which included dose-intensive, systemic, multimodal chemotherapy and triple intrathecal chemotherapy, with empiric dose reductions based on the patient's young age. Additional immunotherapy was given using an anti-CD20 monoclonal antibody, rituximab $375 \mathrm{mg} / \mathrm{m}^{2}$, for 6 doses. Repeat ophthalmology examination revealed reduced swelling of the lids and face (Fig. 3a). Repeat MRI showed resolution of the subperiosteal leukemic infiltrates of the bones (Fig. 3b, c). Repeat bone marrow biopsy and cerebral spinal fluid analyses showed no morphological evidence of residual Burkitt lymphoma/leukemia. 
Fig. 2. a Bone marrow aspirate, Wright stain. $\times 1,000$. The blast cells are large with multilobed nuclei and prominent nucleoli, as well as brightly basophilic cytoplasm and rare cytoplasmic granules. b Bone marrow trephine biopsy, H\&E. $\times 400$. There is infiltration with atypical, vacuolated lymphocytes.
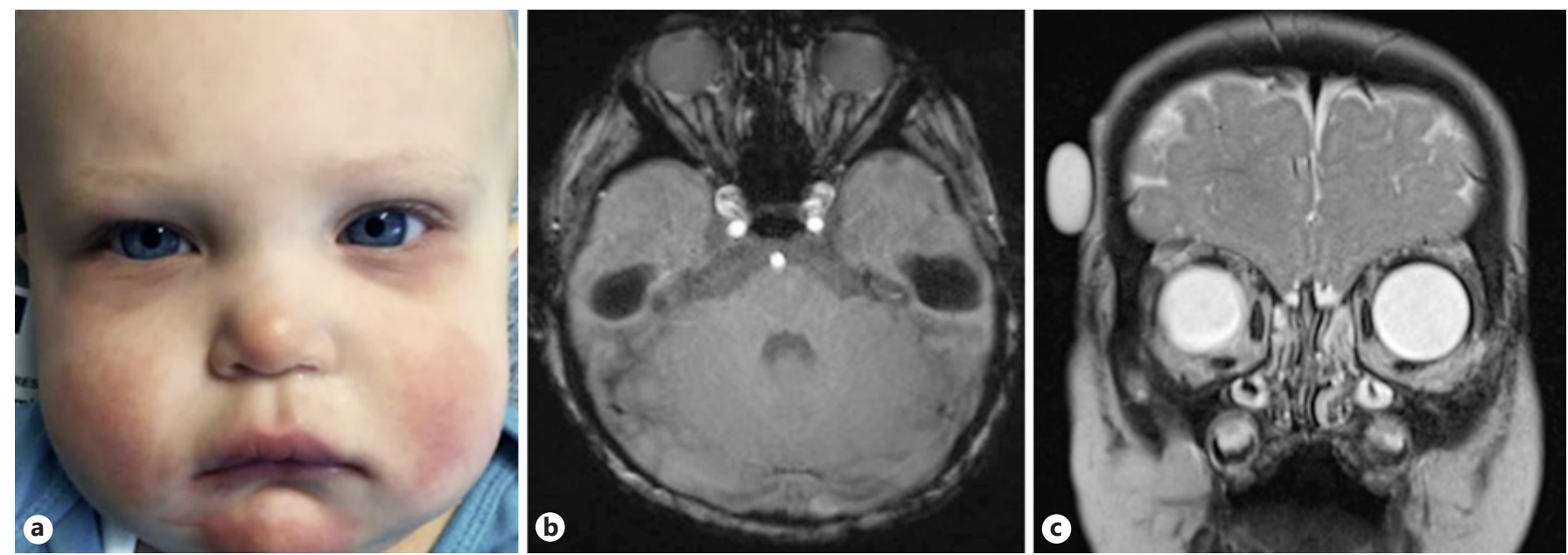

Fig. 3. a External photograph after the chemotherapy regimen and resolution of Burkitt lymphoma with reversal of the facial swelling. b Axial magnetic resonance imaging (MRI) through both orbits reveals a normal architecture and resolution of the infiltrate. c Coronal MRI also shows resolution of the infiltrate.

\section{Discussion}

Burkitt lymphoma is known for its aggressive nature and predominance in the pediatric population [7]. In endemic Burkitt, there is a higher association with EpsteinBarr virus and facial bones, as well as extramedullary involvement [8]. In sporadic forms, extramedullary facial involvement is rare, with primary sites usually being the abdomen and lymph nodes. We present a case of sporadic Burkitt lymphoma in a 7-month-old child with a complex karyotype of isochrome 1q in addition to a translocation between chromosomes 8 and 14 and facial involvement as the first detectable symptom and total resolution as documented by facial photographs and repeat MRI.

A few cases have detailed the development of facial involvement in sporadic Burkitt lymphoma. Most cases have centered on an aggressive, unilateral episode of pro- ptosis, with focal infiltration [7,9-11]. In 1 case series, the infiltration was so focal and pronounced, and progression so rapid, that the initial suspected diagnosis was rhabdomyoscarcoma [11]. Few cases have described a diffusely infiltrative process without focal collection [12]. Our case is unique in that it depicts an expansive, subperiosteal infiltrate more so than a discreet lymphomatous mass. This exceptional presentation, and possible confusion with an infectious or inflammatory process, warrants placing Burkitt lymphoma on the differential in a patient presenting with subtle, widespread facial swelling.

It is critical to recognize the varied presentations of this disease, as prognosis can be poor. Bouali et al. [13] describe a case of a 2-year-old female with right orbital infiltration, who died 6 months after diagnosis. Delayed recognition can also lead to involvement of other facial structures. In 1 case series, Banthia et al. [2] describe a 
very dramatic infiltration pattern of both the orbits and sinuses.

Despite an aggressive presentation and a known natural history of rapid proliferation and early relapses, remission is common with appropriate, intensive treatment, as seen in our patient. To our knowledge, this report is the first to photographically depict the resolution of extramedullary orbital subperiosteal leukemic infiltrates after appropriate chemotherapy $[2,5,9,10,13]$.

\section{Statement of Ethics}

The parents of our patient gave their informed consent, and the institute's committee on human research approved the study protocol.

\section{Disclosure Statement}

No conflicting relationship exists for any author.

\section{References}

1 Burkitt D: A sarcoma involving the jaws in African children. Br J Surg 1958;46:218-223.

-2 Banthia V, Jen A, Kacker A: Sporadic Burkitt's lymphoma of the head and neck in the pediatric population. Int J Pediatr Otorhinolaryngol 2003;67:59-65.

$\checkmark 3$ Gauwerky CE, Croce CM: Chromosomal translocations in leukaemia. Semin Cancer Biol 1993;4:333-340.

$\checkmark 4$ Levine PH, Kamaraju LS, Connelly RR, Berard CW, Dorfman RF, Magrath I, et al: The American Burkitt's Lymphoma Registry: eight years' experience. Cancer 1982;49: 1016-1022.

$>5$ Kearns DB, Smith RJ, Pitcock JK: Burkitt's lymphoma. Int J Pediatr Otorhinolaryngol 1986;12:73-84.
-6 Cairo MS, Gerrard M, Sposto R, Auperin A, Pinkerton CR, Michon J, et al: Results of a randomized international study of high-risk central nervous system B non-Hodgkin lymphoma and B acute lymphoblastic leukemia in children and adolescents. Blood 2007;109: 2736-2743.

7 Grasso D, Borreggine C, Ladogana S, De Santis R, Delle Noci N, Grilli G, et al: Sporadic Burkitt's lymphoma/acute B-cell leukaemia presenting with progressive proptosis and orbital mass in a child. Neuroradiol J 2016;29: 231-235.

8 Orphanidou-Vlachou E, Tziakouri-Shiakalli C, Georgiades CS: Extramedullary hemopoiesis. Semin Ultrasound CT MR 2014;35:255262.

-9 Edelstein C, Shields JA, Shields CL, De Potter P, Eagle RC Jr, Turtel L, et al: Non-African Burkitt lymphoma presenting with oral thrush and an orbital mass in a child. Am J Ophthalmol 1997;124:859-861.
10 Alexander C, George C, Tinatin J, Maia S, Maia M, Mitrofanis P: Orbital Burkitt lymphoma: a case presentation. BMC Ophthalmol 2014;14:109.

11 Gupta R, Yadav JS, Yadav S, Wadood A: Orbital involvement in nonendemic Burkitts lymphoma. Orbit 2012;31:441-445.

12 Carmody J, Misra RP, Langford MP, Byrd WA, Ditta L, Vekovius B, et al: Orbital sporadic Burkitt lymphoma in an adult diabetic African American female and a review of adult orbital cases. Clin Ophthalmol 2011;5: 509-515.

13 Bouali S, Said IB, Yedeas MD, Abderrahmen K, Maatar N, Boubaker A, et al: Primary sporadic Burkitt lymphoma of the orbit, clinical characteristics, management, and outcomes: a case study. Childs Nerv Syst 2016;32:437440 